\title{
O DESENVOLVIMENTO DE COMPETÊNCIAS GERENCIAIS DO ENFERMEIRO NA PERSPECTIVA DE DOCENTES DE DISCIPLINAS DE ADMINISTRAÇÃO APLICADA À ENFERMAGEM
}

\author{
Solange Rothbarth ${ }^{1}$, Lillian Daisy Gonçalves Wolff', Aida Maris Peres ${ }^{3}$
}

\begin{abstract}
${ }^{1}$ Mestranda do Programa de Pós-Graduação em Enfermagem (PPGENF) da Universidade Federal do Paraná (UFPR). Paraná, Brasil. E-mail: solarothbarth@hotmail.com

${ }^{2}$ Doutora em Engenharia de Produção. Professor Adjunto do Departamento de Enfermagem e do PPGENF/ UFPR. Paraná, Brasil. E-mail: ldgw@ufpr.br

${ }^{3}$ Doutora em Enfermagem. Professor Adjunto do Departamento de Enfermagem e do PPGENF/UFPR. Paraná, Brasil. E-mail: amaris@ufpr.br
\end{abstract}

RESUMO: Pesquisa qualitativa, cujo objetivo foi descrever a percepção de docentes de disciplinas de Administração aplicada à Enfermagem sobre o desenvolvimento de competências gerenciais. Os sujeitos constituíram-se de sete enfermeiros que exercem docência em seis instituições de ensino superior de Curitiba-PR. O período para a coleta de dados compreendeu os meses de abril a junho de 2008. A técnica de coleta de dados foi a entrevista semi-estruturada, cujos dados foram submetidos à análise de conteúdo. Foram analisadas sete categorias: definição de competência profissional; dificuldades do enfermeiro no exercício da gerência; competências gerenciais requeridas ao enfermeiro; contribuição da graduação e da prática profissional ao desenvolvimento dessas competências, alternativas para desenvolvê-las ou aperfeiçoá-las, temas que deveriam ser abordados em programas de desenvolvimento gerencial e o papel das organizações empregadoras de enfermeiros. Os sujeitos desvelam o papel relevante da graduação, do próprio enfermeiro e de instituições empregadoras no desenvolvimento e aperfeiçoamento de competências gerenciais.

DESCRITORES: Enfermagem. Competência profissional. Administração em saúde.

\section{DEVELOPING NURSING MANAGERIAL COMPETENCIES FROM THE PERSPECTIVE OF NURSING ADMINISTRATION PROFESSORS}

\begin{abstract}
This descriptive, qualitative research aimed to describe how Nursing Administration professors perceive the development of nursing managerial competencies. The participants were seven Registered Nurses who are nursing professors from six universities from Curitiba-PR, Brasil. Data was collected through semi-structured interviews carried out from April to June of 2008 and then submitted to content analysis. Seven predetermined categories were analyzed: definition of professional competence; nurses' difficulties in managerial practice; managerial competencies required in nursing; contributions of undergraduate course and professional practice in developing these competencies; alternatives for developing or improving these competencies; subjects that should be outlined in managerial development programs and the role of the organizations which hire nurses. The participants unveiled the relevance of the role of the undergraduate courses, the nurses themselves, and the health organizations in developing and improving nursing professional managerial competencies.
\end{abstract}

DESCRIPTORS: Nursing. Professional competence. Health administration.

\section{EL DESARROLLO DE LAS COMPETENCIAS GERENCIALES DEL ENFERMERO EN LA PERSPECTIVA DE LOS PROFESORES DE LAS ASIGNATURAS DE ADMINISTRACIÓN APLICADA A LA ENFERMERÍA}

\begin{abstract}
RESUMEN: Investigación de carácter cualitativo, cuyo objetivo fue describir cómo los profesores de asignaturas de Administración aplicada a la Enfermería perciben el desarrollo de las competencias gerenciales. Los sujetos fueron siete enfermeros profesores en seis instituciones de educación superior en Curitiba-PR, Brasil. La recolección de los datos fue entre abril y junio de 2008. La técnica usada fue la entrevista semiestructurada, siendo sometidas al análisis del contenido. Se analizaron siete categorías predeterminadas: definición de la competencia profesional, dificultades del enfermero en el ejercicio de la gestión, competencias gerenciales necesarias para el enfermero, contribución de los estudios superiores y de la práctica profesional para el desarrollo de estas competencias, alternativas para desarrollarlas o perfeccionarlas, temas que se deben abordar en programas de desarrollo gerencial y el papel de las instituciones empleadoras. Los sujetos destacan el papel relevante de los estudios superiores, del propio enfermero y de las instituciones empleadoras en el desarrollo y mejora de la capacidad de gestión.
\end{abstract}

DESCRIPTORES: Enfermería. Competencia profesional. Administración en salud. 


\section{INTRODUÇÃO}

O principal eixo da prática profissional do enfermeiro é a assistência à saúde. A administração, por meio das funções administrativas, busca organizar a assistência de enfermagem. A administração dos serviços de saúde, por sua vez, sempre esteve ligada ao enfermeiro e assim, no decorrer da história, o gerenciamento dos Serviços de Enfermagem foi incorporado à prática da Enfermagem, inclusive legalmente, como atribuição privativa do enfermeiro. Dessa forma, o gerente de enfermagem é o responsável por coordenar o Serviço de Enfermagem e tomar decisões, a fim de garantir uma assistência de qualidade. ${ }^{1}$ Portanto, é necessário que este profissional seja competente para tal, ou seja, tenha conhecimentos, habilidades e atitudes que, quando mobilizados ajudam-no a desempenhar bem as suas funções.

Ademais, a graduação, por meio de disciplinas de Administração aplicada à Enfermagem, deve preparar os graduandos para a atuação gerencial, oferecendo possibilidades de se desenvolverem do ponto de vista teórico, como oportunidades para o exercício prático, contribuindo de diferentes maneiras para a aquisição e desenvolvimento das competências gerenciais do enfermeiro. Todavia, os graduandos não desenvolvem plenamente essas competências durante a formação. Já como profissionais, deverão assumir compromisso pessoal e com a sociedade de continuarem estudando para as aperfeiçoarem, continuamente. ${ }^{2}$

No entanto, a literatura tem apontado para o fato de que o conhecimento dos enfermeiros sobre o processo de trabalho gerencial é ainda incipiente, diante de sua importância e complexidade. ${ }^{1}$ Tal como citado, o profissional enfermeiro precisa ter interesse em adquirir, desenvolver e aperfeiçoar constantemente as competências gerenciais, o que pode acontecer mediante a participação em cursos de pós-graduação, educação continuada, entre outras inúmeras possibilidades. Entretanto, as organizações tem um papel importante e devem investir no desenvolvimento profissional de seus colaboradores..$^{2-4}$

A concepção de competências que fundamentou a realização desta pesquisa considera as três dimensões distintas que interferem na formação das competências: a pessoal ou singular; a das organizações ou particular; a dos países ou estrutural. ${ }^{3} \mathrm{O}$ conceito de competência contempla um saber agir responsável, que implica em mobilizar, integrar e transferir conhecimentos, recursos e habilidades, num contexto profissional determi- nado. No mundo do trabalho, o desenvolvimento de competências, ao agregar valor econômico à organização deve permitir que valores pessoais e sociais sejam agregados aos indivíduos. ${ }^{5}$

No entanto, seria ingênuo ignorar as influências advindas do plano estrutural das macro-políticas para a efetivação dos modelos de formação de competências nas dimensões singular e particular. $\mathrm{Na}$ Enfermagem, o modelo de formação de competências é orientado pelas Diretrizes Curriculares Nacionais que vislumbram como principais competências a serem trabalhadas pelas instituições de ensino na formação do enfermeiro: a atenção à saúde, a tomada de decisões, a liderança, a comunicação, a administração e gerenciamento e a educação permanente. ${ }^{3-6}$

Ao lembrar que na Enfermagem, o gerenciamento foi historicamente incorporado como função do enfermeiro, as competências gerenciais para a prática da gerência da assistência podem ser conceituadas como conhecimentos, habilidades e atitudes que possibilitam que o enfermeiro e a equipe liderada por ele exerçam seu trabalho na busca de resultados eficientes. ${ }^{6}$

Por sua vez, docentes que se dedicam às disciplinas de Administração aplicada à Enfermagem se aprofundam no conhecimento relativo ao desenvolvimento de competências gerenciais, atuam junto a alunos de graduação e acompanham a prática gerencial de enfermeiros em instituições de saúde. Considerando-se esta experiência, a presente pesquisa teve como objetivo descrever a percepção de docentes sobre o desenvolvimento de competências gerenciais do enfermeiro. A motivação para a sua realização surgiu da expectativa de que seus resultados venham a fornecer subsídios para reflexão por parte da academia, dos serviços e dos enfermeiros sobre os redirecionamentos necessários ao aprimoramento das competências gerenciais desses profissionais, que indubitavelmente tem grande potencial para contribuir para a qualidade dos serviços de saúde.

\section{MÉTODO}

Trata-se de uma pesquisa descritiva-exploratória de abordagem qualitativa, realizada em seis Instituições de Ensino Superior (IES) privadas e uma pública, que oferecem o Curso de Enfermagem em Curitiba-PR. Foram obtidas autorizações formais de seus respectivos diretores e coordenadores de curso e o projeto da pesquisa foi aprovado em 28 de maio de 2008 no Comitê de Ética em Pesquisa do Setor de Ciências da Saúde 
da Universidade Federal do Paraná com o $\mathrm{N}^{\mathrm{o}}$ 487.024.08.03, por estar de acordo com a Resolução No 196/96 do Conselho Nacional de Saúde, que dispõe sobre a pesquisa com seres humanos.

Os sete sujeitos participantes foram enfermeiras docentes de Cursos de Graduação em Enfermagem de IES de Curitiba-PR, que ao serem convidadas por telefone aceitaram participar da pesquisa. Os critérios de inclusão dos sujeitos foram: ser enfermeiro docente de curso de graduação em enfermagem, que já formou pelo menos uma turma; com experiência mínima de dois anos em disciplinas relacionadas à Administração aplicada à Enfermagem, que aceitasse participar da pesquisa e assinar o Termo de Consentimento Livre e Esclarecido (TCLE). Somente uma IES curitibana não aceitou participar do estudo, e em uma IES privada duas docentes aceitaram participar da pesquisa. O número inicial de sujeitos foi considerado adequado, uma vez que " [...] a opção pela profundidade é a prioridade do pesquisador qualitativo, em detrimento da amplitude do estudo". 7:19 Este fato foi corroborado pela saturação dos dados constatada na análise dos dados.

A coleta de dados ocorreu no período compreendido entre os meses de abril e junho de 2008, por meio da realização de entrevistas semiestruturadas com os sujeitos. Esta técnica é útil para pesquisas qualitativas, pois "[...] garante que o pesquisador obterá todas as informações requeridas (sem esquecer uma questão), enquanto, ao mesmo tempo, dá ao participante liberdade para responder e ilustrar conceitos". 8:286

Para a realização da entrevista foi elaborado um roteiro, composto por dados de caracterização do sujeito e oito perguntas norteadoras. Uma testagem do roteiro de entrevista foi realizada com uma docente que atendia aos critérios de inclusão, mas que não fez parte do grupo de sujeitos, e este foi avaliado como adequado aos objetivos da pesquisa.

Um primeiro contato pessoal com cada sujeito visou a apresentação da proposta de pesquisa e marcação da entrevista em data, local e horário indicados por ele. O tempo de entrevista variou entre 15 e 30 minutos. Conforme previsto no TCLE, utilizou-se um gravador para registro da entrevista e transcrição de seu conteúdo na íntegra.

A Análise de Conteúdo (AC) foi eleita como método de análise dos dados, na modalidade temática, por destacar o tema como unidade de significação que permite descobrir os 'núcleos de sentido' que compõem uma comunicação, carac- terizados pela importância das unidades de significação encontradas. ${ }^{9}$ Por meio da AC, buscou-se "[...] compreender o pensamento do sujeito através do conteúdo expresso no texto, numa concepção transparente de linguagem". ${ }^{10: 683}$

A análise incluiu os seguintes passos: 1atribuição de um código a cada um dos sujeitos, constituído da letra d e um número cardinal de 1 a 7; 2- leitura inicial minuciosa e exaustiva do texto transcrito da entrevista; 3- identificação e numeração das Unidades de Significado (USs). Cabe ressaltar que as categorias de análise foram pré-definidas, a partir das perguntas norteadoras contempladas no roteiro de entrevista; 4- seleção das USs que guardavam pertinência com tais categorias; 5- transcrição destas para a linguagem da pesquisadora, de modo a explicitar o seu sentido; 6- descoberta dos núcleos de sentido e 7-interpretação e discussão dos núcleos.

\section{RESULTADOS E DISCUSSÃO}

As disciplinas de Administração aplicada à Enfermagem nas IES, tem denominações diversas, como por exemplo: Gestão do Processo de Trabalho em Enfermagem; Administração em Enfermagem; Administração de Serviços de Saúde; Teorias, Modelos e Gestão em Saúde. São ofertadas a partir do quinto período do curso de graduação em enfermagem. Apenas uma instituição concentra todo o conteúdo relacionado à área administrativa em apenas um período, correspondendo ao oitavo período do curso de graduação. A carga horária destinada a essas disciplinas varia entre os cursos entre 306 horas a 792 horas, distribuídas em blocos teórico-práticos. A distribuição desta carga horária total varia entre os períodos e as instituições, no entanto pode-se afirmar que ela está mais concentrada nos últimos períodos do curso. Neste aspecto destaca-se que duas instituições possuem uma carga horária de aproximadamente 500 horas, alocadas no último período do curso.

A maioria das sete enfermeiras docentes participantes da pesquisa graduou-se entre 24 e 31 anos atrás, com exceção de uma delas que tem 39 anos de atuação profissional, e de outra que tem 10 anos. Três delas trabalham há menos de 10 anos na instituição de ensino superior, e quatro há mais de 20 anos. Em relação ao tempo de exercício da docência em disciplinas relacionadas à Administração aplicada à Enfermagem, a mais experiente delas tem 22 anos nessa docência a menos experiente tem quatro e as demais tem entre 10 e 15 anos; o que evidencia sua aptidão a responderem 
às perguntas realizadas sobre o desenvolvimento gerencial do enfermeiro.

A seguir apresenta-se a síntese das categorias de análise: definição de competência profissional; dificuldades do enfermeiro no exercício da gerência; competências gerenciais requeridas ao enfermeiro; contribuição da graduação e da prática profissional para o desenvolvimento de competências; alternativas para desenvolver ou aperfeiçoar competências; temas que deveriam ser abordados em programas de desenvolvimento gerencial e o papel das organizações empregadoras de enfermeiros.

Os sujeitos concordam que competência profissional é a "[...] capacidade de articular e mobilizar conhecimentos, habilidades e atitudes, colocando-os em ação para resolver problemas e enfrentar situações de imprevisibilidade em dada situação e contexto cultural" $.11: 13$ No entanto, afirmam que, no caso das competências gerenciais, a articulação e mobilização de conhecimentos, habilidades e atitudes devem ser aplicadas em toda e qualquer situação, previsível ou planejada, envolvendo tanto aspectos clínicos como administrativos, e mediante uma postura pró-ativa, conforme expresso em algumas das falas.

[...] eu não acredito que seria só para resolver problemas [...] mas numa tentativa ter uma visão mais pró-ativa das habilidades gerenciais [...] (d2).

[...] a competência profissional é para atuar em toda e qualquer situação previsível ou não. [...] Devese acrescentar ao conceito, a articulação e mobilização dos três itens - conhecimento, habilidades e atitudes, seja do ensino clínico ou do ensino administrativo para planejar, coordenar, direcionar e avaliar o processo de assistir em enfermagem [...] (d6).

Os seus discursos coincidem com a afirmação de que a competência profissional abrange além da aplicação adequada do conhecimento em situações reais, habilidades interpessoais, técnicas e pensamento crítico. ${ }^{12}$ Conseqüentemente, a competência traz a idéia de algo dinâmico e, dessa forma, o seu próprio conceito não consiste em algo acabado, mas sim em um processo em construção. ${ }^{13}$

Entre as dificuldades do enfermeiro no exercício da gerência, apontadas pelos sujeitos, destacam-se: o desconhecimento sobre gerenciamento, a distinção entre o gerenciamento do cuidado e do serviço, e o conceito de competência; a falta de habilidades técnicas, humanas (relacionamento interpessoal, relação funcionário-gerente) e conceituais; a visão dicotômica dos modelos gerenciais apresentados na graduação e dos vigentes no mercado de trabalho; dificuldades na tomada de decisão; dificuldade em liderar a equipe e no desenvolvimento de habilidades para o planejamento, coordenação e avaliação do processo gerencial e do cuidado. As seguintes falas exemplificam algumas dificuldades.

[...] a compreensão do que é a função gerencial. Para muitos a função gerencial está mais ligada às atividades administrativas da organização hospitalar, entendem que a sua função é atender as necessidades institucionais e não do paciente ou da equipe (d6).

[...] hoje não se faz uma distinção entre o gerenciamento do serviço e o gerenciamento do cuidado [...] no gerenciamento do serviço [...] é unidade de negócios que eu estou gerenciando, é fazer esta unidade se desenvolver, estar alinhada com todas as tendências do mercado [...] a gerência do cuidado é canalizada especificamente para o paciente, $[. .$.$] quais são as necessidades dele, [. .$. o que ele precisa de cuidado, de orientação [...] Estas duas gerências não podem ser executadas pela mesma pessoa. [...] Não se tem condições de acumular estas duas funções (d5).

Muitas dificuldades apontadas pelos sujeitos são descritas na literatura correlata ao tema, a exemplo do conhecimento dos enfermeiros sobre o trabalho administrativo ser ainda incipiente. Em estudo realizado com enfermeiros, em que foi investigada a visão que estes tem do processo de trabalho gerencial de enfermagem, foram obtidas evidências de que alguns não tem intimidade com o termo gerência em enfermagem e não tem claro o processo de trabalho gerencial do enfermeiro. ${ }^{1}$ Outros autores afirmam que o enfermeiro tem sentido dificuldade em articular a prática assistencial e gerencial, optando por concentrar-se na função administrativa e, conseqüentemente, distancia-se do cuidado direto ao paciente. Isto, talvez, se deva ao "[...] despreparo do enfermeiro e à maneira desarticulada com que algumas instituições de ensino abordam esses conteúdos e os relacionam com a prática cotidiana do trabalho; prática esta que sofre grande influência dos valores culturais das organizações onde se desenvolve". ${ }^{14: 2}$

A categoria competências gerenciais requeridas ao enfermeiro contempla aspectos relacionados a conhecimentos, habilidades e atitudes, e pode ser analisada em duas subcategorias distintas: competências gerenciais relativas ao processo administrativo e competências gerenciais relacionadas ao cuidado.

A classificação da primeira subcategoria apresenta a necessidade de conhecimentos sobre questões administrativas, processo de trabalho, 
processo de tomada de decisão, administração de conflitos, administração de custos, e saber como analisar a situação e articular os recursos disponíveis com as necessidades e a realidade. Quanto às habilidades, estas são relacionadas às técnicas, conceituais e humanas; processuais - planejamento, organização, coordenação, direção e avaliação; de liderança; de tomar decisão; de comunicação; de observação; raciocínio crítico; trabalhar em equipe e de auto-avaliação. Já entre as atitudes, destacase a importância de demonstrar interesse pelas questões gerenciais, promover o desenvolvimento da equipe (educação continuada); educar a equipe; demonstrar responsabilidade pelo seu desenvolvimento e aperfeiçoamento profissional.

É preciso ter um conhecimento amplo [...] não só voltado à enfermagem, mas voltados à área administrativa, a uma área de preços, valores, [...] uma tomada de decisão baseada nos indicadores de avaliação. [...] os diversos processos de trabalho, o conhecimento de cada um deles. Como é que ocorre na instituição, [...] não só o processo de trabalho do enfermeiro, [...] conhecimento técnico do cuidado (d1).

[...] habilidades que a gente desenvolve a partir da liderança, [...] deve estar sempre voltado para a educação, tem que ter a competência e habilidade humana, eu acho que é a mais importante. [...] tem que ter bastante [...] habilidade conceitual [...] (d2).

[...] éo interesse pelas questões gerenciais [...] pelo conhecimento das questões gerenciais [...] uma competência que a gente tem que desenvolver é a capacidade de coordenar este processo de cuidar com qualidade (d3).

Sobre o desenvolvimento da competência administrativa e gerencial do enfermeiro, é indispensável o conjunto de conhecimentos identificados para planejar, tomar decisão, interagir e gerenciar pessoal. O domínio das técnicas administrativas auxilia o trabalho gerencial, entretanto a atuação gerencial requer habilidades mais complexas que não somente o domínio das técnicas administrativas. ${ }^{3: 82}$ Assim, não basta ser gerente, é necessário ser um bom gerente. E para isso é necessário possuir características inerentes a esta condição, bem como ser capaz de mobilizar conhecimentos, habilidades e atitudes e, além disso, aplicá-los em situações reais e concretas, de forma individual ou na coletiva com a equipe de trabalho. ${ }^{1}$

$\mathrm{Na}$ subcategoria competências gerenciais relacionadas ao cuidado ressaltam-se os conhecimentos sobre: como planejar e coordenar o processo de cuidar; o papel do enfermeiro na equipe de enfermagem e na assistência de enfermagem; conhecimento técnico - científico; atenção à saúde.
Entre as habilidades de destaque está a clínica (cuidar competente); comunicação no relacionamento interpessoal e no interprofissional; e saber registrar. Sobre as atitudes são relevantes: agir profissionalmente; demonstrar responsabilidade e ter comprometimento com a assistência de enfermagem ao paciente; agir prospectivamente; e articular politicamente. Os discursos a seguir evidenciam essas competências: [...] visão prospectiva, se antever, planejar, coordenar, direcionar as situações relacionadas para atender as necessidades de saúde relacionadas ao processo de cuidar em enfermagem [...] a comunicação, o relacionamento profissional com a equipe de enfermagem, com a equipe de saúde e com os demais profissionais da estrutura organizacional, [...] a comunicação escrita, o registro documental do processo de cuidar e da instituição. [...] a liderança no sentido de coordenação e direção da assistência de enfermagem. [...] saber o que, como, quando, com quem, por que fazer e aonde chegar. [...] tomar [...] decisões [...] dar direção aos demais integrantes da equipe [...] (d6).

[...] o que falta no enfermeiro é a atitude profissional, [...] ele é profissional e tem que tomar decisões. Ele tem hoje uma atitude muito paternalista [...] falta uma relação profissional na equipe. [...] ter atitude e responsabilidade frente [...] a assistência ao paciente, [...] uma decisão gerencial é o suporte para o cuidado (d1).

Tratando deste tema, autores destacam a liderança, a comunicação, a motivação da equipe e a competência interpessoal como competências importantes para a prática gerencial do enfermeiro, ${ }^{6}$ como também o gerenciamento de conflitos, uma vez que o enfermeiro diariamente se depara com situações diversas que exigem dele tomada de decisão, flexibilidade, resolução de problemas, gerenciamento de conflitos, coordenação da equipe e planejamento, a fim de atingir os objetivos da organização e dos pacientes. ${ }^{15}$

Dessa forma, a síntese sobre as competências requeridas do enfermeiro na prática gerencial é de que esta deve incluir " [...] atividades de líder, responsável pela gestão de pessoas e de gerente que administra os recursos financeiros, materiais e físicos que se caracterizam por atividades importantes para a sobrevivência organizacional". 2:60

Competências gerenciais são indispensáveis para que talentos sejam potencializados e a aprendizagem coletiva seja ampliada. Logo, a atuação gerencial requer conhecimento, habilidades e atitudes com vistas à eficácia e à eficiência. ${ }^{3-12}$ Todavia, definir as competências necessárias aos enfermeiros e estabelecer estratégias para desenvolvê-las, dentro e fora das organizações 
de saúde, constitui-se um grande desafio. Nesta perspectiva, estudos sobre a prática gerencial do enfermeiro tem mostrado que as competências devem ser discutidas a fim de se dar respostas às necessidades desta prática. ${ }^{6}$

De acordo com os sujeitos, a contribuição da graduação e da prática profissional para o desenvolvimento de competências acontece de diferentes maneiras no gerenciamento do serviço e no gerenciamento do cuidado. De modo geral, as disciplinas curriculares abordam os conceitos básicos e apontam diretrizes para tais processos. Contudo, é papel do professor de disciplinas de Administração aplicada à Enfermagem discutir com o aluno a relação da teoria com a realidade da prática gerencial. Isso é possível pelo desenvolvimento de atividades teórico-práticas junto a serviços de saúde que aproximam o aluno à prática gerencial de enfermeiros. Como resultados de aproximações teóricas e reflexivas com o auxílio docente, o aluno ampliará seu entendimento sobre a intersecção entre o gerenciamento do serviço e do cuidado, entre outros objetivos do seu processo de ensino-aprendizado.

Ele deverá aprender a mobilizar e articular os conhecimentos adquiridos na graduação, de forma que se torne um profissional capaz de aliar questões gerenciais e assistenciais de modo que não perpetue o modelo dicotomizado de assistência e gerência que se encontra no mercado de trabalho. No entanto, os sujeitos apontam para o fato de que não é possível desenvolver todas as competências gerenciais do graduando devido à duração do curso bem como a fatores como o interesse pelo aprendizado e maturidade do aluno.

A graduação dá o primeiro impulso, depois tem que ser bastante trabalhado durante toda a vida (d5).

[...] a partir da graduação nos outros cursos de atualização, de desenvolvimento e de especialização ele vai incorporando o restante [...] (d5).

Na graduação, o básico ele recebe. [...] quando vai para o estágio na parte gerencial, [...] você procura mostrar como utilizar as diversas ferramentas da gestão, as administrativas: de planejamento, de organização, direção e controle, [...] mostrar para que serve tomar uma decisão na hora certa. [...] a gente consegue mostrar alguns caminhos, mas não consegue desenvolver tudo por que é inviável pelo tempo (d1).

A maioria dos sujeitos (d1, d2, d4, d5, d6 e d7) afirmou que as competências gerenciais podem ser desenvolvidas ou aperfeiçoadas de muitas maneiras durante a vida profissional do enfermeiro. A com- petência é construída, aprimorada e renovada de forma permanente, ${ }^{13} \mathrm{em}$ um fluxo que requer aprendizado contínuo. Entretanto, não basta aprender, é preciso empreender. Logo, o aluno deve apreender que após a sua graduação ele se compromete consigo mesmo e com a sociedade em "[...] manter-se constantemente atualizado, incorporando os novos conhecimentos e enfoques $[\ldots . .]^{\prime \prime}$. 2:34

Eu acho que ele pode aperfeiçoar no estudo a na pesquisa depois que ele se forma. Ele tem que sair [...] consciente de que esta é uma questão inerente ao enfermeiro [...] ele tem que buscar [...] através do estudo, da pesquisa, fazendo especialização (d7).

Entre outras maneiras de desenvolver competências gerenciais, apontadas pelos entrevistados, destacam-se: o estudo individual dos enfermeiros e a sua participação em discussões com alunos e professores das disciplinas de Administração aplicada à Enfermagem, durante atividades teórico-práticas desenvolvidas em seu local de trabalho. Entretanto, os sujeitos ressaltam que a realização e participação em pesquisas, entre os enfermeiros, ainda é incipiente, pois se observa que a área gerencial desperta pouco interesse para as pesquisas de pós-graduação, havendo preferência pela área assistencial.

Outras formas facilitadoras do desenvolvimento de competências gerenciais citadas pelos sujeitos foram: participação em programas de desenvolvimento pessoal e profissional, tais como cursos de aperfeiçoamento, pós-graduação (especialização e mestrado), voltados para a área de administração, economia e gestão em saúde; bem como a participação em grupos de pesquisa. Todos os sujeitos justificam que muitas mudanças ocorrem e isto requer que o mesmo estude e se atualize constantemente. Ademais, é necessário que o profissional tenha flexibilidade e saiba identificar em que situações seus conhecimentos podem ser mobilizados e articulados. Estas idéias são esclarecidas nas seguintes falas: [...] nestas duas últimas décadas a gente tem passado por mudanças cruciais no modelo gerencial e se a gente não se alinhar a esses novos modelos, não estudá-los, não entendê-los, [...] a gente fica completamente defasado (d5).

[...] essas competências mudam muito. Uma pessoa que era competente há dez anos hoje não é mais, [...] para você se manter competente bastante tempo exige muita flexibilidade do sujeito. A pessoa precisa ser muito flexivel, ter um perfil mais adaptativo. [...] a pessoa [...] tem que estar agregando e saber que em qual momento aquele conhecimento pode ser mobilizado (d4). 
Uma pessoa só pode ser considerada atualizada por um momento, portanto deve inovar e transformar-se. ${ }^{2}$ Essa afirmativa corrobora o fato de a competência ser "[...]definida e construída na prática social. É uma tarefa conjunta entre a empresa, trabalhadores e educadores. [...] não é abstrata, pois provém de uma reflexão sobre a realidade do mundo do trabalho" ${ }^{16: 12}$

Adicionalmente, "[...] a formação profissional de qualidade deve ter sólida base de formação geral, que não se completa na escola, mas sim dentro do processo evolutivo do ser humano, por meio da educação permanente. Desse modo, ocorre a complementação para a formação integral do indivíduo". ${ }^{12: 337}$

Segundo os sujeitos, são temas que deveriam ser abordados em programas de desenvolvimento de competências gerenciais do enfermeiro: conteúdos tradicionais trabalhados nas disciplinas de administração (d4, d5, d6, d7); processo de trabalho de enfermagem $(\mathrm{d} 1, \mathrm{~d} 3)$; processo administrativo (d1, d3); processo decisório (d1, d2, d4, $\mathrm{d} 7$ ); gerenciamento de serviço e gerenciamento do cuidado (d1, d3); competências gerenciais (d6); instrumentos gerenciais $(\mathrm{d} 7)$; liderança $(\mathrm{d} 2, \mathrm{~d} 4$, $\mathrm{d} 7$ ); gerenciamento de recursos humanos (d7); habilidades humanas (d2, d7); administração de conflitos (d1) cultura organizacional (d2); comunicação (d1, d4); políticas de saúde (d4); modelo de atenção (d5); modelos gerenciais (d5); sistematização da assistência de enfermagem (d1); temas sobre economia em saúde (d1); o serviço de saúde visto como uma empresa (d5); gerenciamento de custos $(\mathrm{d} 1, \mathrm{~d} 5)$; gerenciamento e racionalidade na utilização de recursos materiais (d1, d7); novas tecnologias para a gerência e para o cuidado $(\mathrm{d} 3, \mathrm{~d} 4)$.

O perfil do gerente deve estar baseado em habilidades e competências para assegurar uma prática de qualidade. ${ }^{2}$ No caso do enfermeiro, ele necessita de conhecimentos relacionados ao gerenciamento dos recursos físicos, materiais, humanos, financeiros, políticos e de informação, ${ }^{6}$ bem como "[...] o uso dos instrumentos e funções gerenciais como planejamento, dimensionamento de pessoal, recrutamento e seleção, educação continuada, liderança, supervisão, e avaliação de desempenho, a fim de prestar uma assistência de enfermagem de qualidade" ${ }^{17: 373}$ Entretanto, cabe ressaltar que é essencial o desenvolvimento da capacidade de liderança do enfermeiro a fim de aprimorar a sua prática gerencial, o que deve ser fomentado pelas organizações empregadoras. ${ }^{18}$
Os sujeitos referem que as organizações empregadoras são também responsáveis pelo desenvolvimento gerencial de enfermeiros, uma vez que é seu papel investir em recursos humanos, capacitando-os mediante a oferta de cursos, de educação permanente e viabilizando a sua participação em cursos de pós-graduação. Entretanto, também devem cobrar dos enfermeiros resultados que reflitam na qualidade do serviço.

[...] ela deve estar investindo na capacitação. [...] ela tem que fazer investimentos monetários oferecendo cursos de capacitação, formação continuada, especialização. [...] a própria instituição contratante tem uma responsabilidade no investimento [...] Tem que investir, mas tem que dar o troco que é a melhoria na qualidade do serviço. [...] Se eu quero ter um padrão assim eu tenho que ter um profissional num padrão assim (d1).

Todavia, os sujeitos afirmam que as organizações não investem ou, investem pouco no desenvolvimento de competências gerenciais de seus enfermeiros, por não estarem preparadas para tal. Isso remete ao fato de que não somente os profissionais devem buscar atualização, mas as organizações também devem investir no seu desenvolvimento e dos seus profissionais. "É inquestionável nos dias de hoje, para a maioria das organizações, a necessidade de capacitar seus profissionais, por meio de uma educação reflexiva e participativa". ${ }^{19: 138}$ Não há como negar que as organizações investem no desenvolvimento dos profissionais para um desempenho adequado da função e facilitar o alcance dos objetivos e dos resultados pretendidos por ela. Portanto, o investimento em desenvolvimento das pessoas é um grande desafio. Embora seja "[...] reconhecido como estratégia para melhorar a qualidade do pessoal de Enfermagem, parece não ser devidamente valorizado em algumas instituições [...]". 2:27 Sendo assim, os enfermeiros buscam cursos de atualização para suprir as lacunas deixadas pela graduação ou pelo descomprometimento das organizações com o seu desenvolvimento profissional. ${ }^{3}$

\section{CONCLUSÃO}

Os sete sujeitos da pesquisa admitem que a competência gerencial implica articulação e mobilização pró-ativa de conhecimentos, habilidades e atitudes em toda e qualquer situação, previsível ou não, enfocando tanto aspectos administrativos como clínicos. Contudo, reconhecem que os enfermeiros têm dificuldades no exercício de suas funções gerenciais. Destacam o desconheci- 
mento destes acerca de: conceito de competência gerencial, gerenciamento do cuidado e gerenciamento do serviço, habilidades técnicas, humanas, conceituais e processuais necessárias ao gerente. Ressaltam a dicotomia entre os modelos gerenciais apresentados na graduação e os vigentes no mercado de trabalho, e as dificuldades em exercer a liderança e tomar decisões.

A graduação contribui para o desenvolvimento de competências gerenciais, principalmente quando propicia ao aluno experiências de participação na prática gerencial do enfermeiro e de discussões com os professores, aliando a teoria e a prática. Entretanto, é necessário que se busque o aperfeiçoamento que pode ser adquirido na prática gerencial ou em cursos de aperfeiçoamento e pós-graduação. As instituições empregadoras, tem co-responsabilidade e compromisso com o desenvolvimento gerencial de seus colaboradores e devem avaliar o retorno de seu investimento em termos de melhoria da qualidade dos serviços e da assistência à clientela.

São pertinentes as percepções dos docentes quanto ao domínio teórico-prático de conteúdos necessário para o desenvolvimento gerencial de enfermeiros. Contudo, enfatiza-se que é também indispensável à mobilização de atitudes voltadas à inovação e implementação de estratégias de mudanças, que transformem a realidade da assistência à saúde de modo condizente com as demandas do atual movimento político sanitário brasileiro. Neste sentido, compete aos docentes de disciplinas de Administração aplicada à Enfermagem facilitarem aos alunos experiências em unidades de saúde que buscam continuamente, e de maneira proativa, mudanças incrementais indispensáveis para a construção de cenários favoráveis ao desenvolvimento do Sistema Único de Saúde. Assim impulsionarão o desenvolvimento gerencial de futuros enfermeiros a partir de experiências favoráveis e positivas, que servirão de referências como boas práticas gerenciais, que possam ser aplicadas em sua vida profissional e que contribuam para o atendimento efetivo das necessidades de saúde da população.

\section{REFERÊNCIAS}

1. Sanches VF, Christovam BP, Silvino ZR. Processo de trabalho do gerente de enfermagem em unidade hospitalar - uma visão dos enfermeiros. Esc Anna Nery Rev Enferm. 2006 Ago; 10(2):214-20.

2. Bezerra ALQ. O contexto da educação continuada em enfermagem. São Paulo (SP): Lemar e Martinari; 2003
3. Peres AM. Competências gerenciais do enfermeiro: relação entre as expectativas da instituição formadora e do mercado de trabalho [tese]. São Paulo (SP): Universidade de São Paulo. Escola de Enfermagem; 2006.

4. Ricaldoni CAA, Sena RR. Educação permanente: uma ferramenta para pensar e agir no trabalho de enfermagem. Rev Latino-am Enfermagem. 2006 Nov-Dez; 14(6):837-42.

5. Le Bortef G. De la compétence: essai sur um attracteur étrange. Quatrième Tirage. Paris (FR): Les Éditions d'organisation; 1995.

6. Cunha ICKO, Neto FRGX. Competências gerenciais de enfermeiras: um novo velho desafio? Texto Contexto Enferm. 2006 Jul-Set; 15(3):479-82.

7. Matheus MCC. Pesquisa qualitativa em enfermagem. São Paulo (SP): Livraria Médica Paulista; 2006.

8. Turato ER. Tratado da metodologia clínicoqualitativa: construção teórico-epistemológica, discussão comparada e aplicada nas áreas da saúde e humanas. Petrópolis (RJ): Vozes; 2003.

9. Minayo MCS. O desafio do conhecimento: pesquisa qualitativa em saúde. $8^{a}$ ed. Rio de Janeiro (RJ): Hucitec; 2004.

10. Caregnato RCA, Mutti R. Pesquisa qualitativa: análise de discurso versus análise de conteúdo. Texto Contexto Enferm. 2006 Out-Dez; 15(4):679-84.

11. Deluiz N. Qualificação, competências e certificação: visão do mundo do trabalho. Formação. 2001 Mai; 1(2):3-15.

12. Paschoal AS, Mantovani MF, Lacerda MR. A educação permanente em enfermagem: subsídios para a prática profissional. Rev Gaúcha Enferm. 2006 Set; 27(3):336-43.

13. Coelho CAG. Proposta pedagógica: o campo de ação. Brasília (DF): Fundação Oswaldo Cruz, Escola Nacional de Saúde Pública; 2000.

14. Martins VA, Nakao JRS, Fávero N. Atuação gerencial do enfermeiro na perspectiva dos recém-egressos do curso de enfermagem. Esc Anna Nery Rev Enferm. 2006 Abr; 10(1):101-8.

15. Simões ALA, Fávero N. O desafio da liderança para o enfermeiro. Rev Latino-am Enfermagem. 2003 SetOut; 11(5):567-73.

16. Lazzaroto EM. Competências essenciais requeridas para o gerenciamento de Unidades Básicas de Saúde [dissertação]. Florianópolis (SC): Universidade Federal de Santa Catarina. Programa de PósGraduação em Engenharia da Produção; 2001.

17. Mazur CS, Labronici L, Wolff LDG. Ética e gerência no cuidado de enfermagem. Cogitare Enferm. 2007 Jul-Set;12(3):371-76.

18. Galvão CM, Trevizan MA; Sawada NO; Coleta JAD. Liderança situacional: estrutura de referência para o trabalho do enfermeiro-líder no contexto hospitalar. Rev. Latino-am. Enfermagem. 1998 Jan; 6(1):81-90. 
19. Peres HHC, Leite MMJ, Gonçalves VLM. Educação continuada: recrutamento e seleção, treinamento e desenvolvimento, e avaliação de desempenho pro- fissional. In: Kurcgant P, organizador. Gerenciamento em enfermagem. Rio de Janeiro (RJ): Guanabara Koogan; 2005. p.138-56. 